\title{
On Application of Rhetorical Devices to Cosmetic Advertisements
}

\author{
Jintao Shi \\ School of Foreign Languages, Dalian Maritime University, Dalian, China \\ Email: 1316121845@qq.com
}

How to cite this paper: Shi, J. T. (2021). On Application of Rhetorical Devices to Cosmetic Advertisements. Open Journal of Modern Linguistics, 11, 315-326. https://doi.org/10.4236/ojml.2021.113025

Received: April 12, 2021

Accepted: May 29, 2021

Published: June 1, 2021

Copyright $\odot 2021$ by author(s) and Scientific Research Publishing Inc. This work is licensed under the Creative Commons Attribution International License (CC BY 4.0).

http://creativecommons.org/licenses/by/4.0/

\section{(c) (i) Open Access}

\begin{abstract}
The first part of this paper, as an introduction, mainly describes the definition of advertising, characteristics of advertising, and functions; the second part uses the literature research method to summarize the development course of Chinese cosmetics advertising, and it also summarizes the previous studies on cosmetics advertising and rhetoric; in the third part, the paper mainly explores the application and effect of rhetoric in advertising. In the fourth part, the author points out the problems of rhetoric in cosmetic advertisement and the causes of these problematic phenomena. In the end, the author summarizes the research findings of this paper and puts forward some suggestions for the standardization of cosmetics advertising.
\end{abstract}

\section{Keywords}

Cosmetic Advertisement, Rhetorical Device

\section{Introduction}

\subsection{Definition of Advertisement}

In a broad sense, advertising is intended to create benefits for the government, political parties, religion, education, etc. without the aim of getting revenue; in the narrow sense, it refers to the advertisement which is used to make income. It usually is a commercial advertisement or economic advertisement. It is a means for industrial and commercial enterprises to sell commodities or provide services through paying and spreading information about commodities or services to consumers or users through advertising media.

Cosmetic advertisement, especially, is the product of people's pursuit of beauty and youth. In the era of personalized consumption, consumers value spiritual satisfaction more than the use-value of products (Zhang, 2010). Such as the car, 
the watch is no longer only a means of transportation and measuring instruments, but more representative of a person's identity. The role of cosmetics is to care for and improve the skin, cover up facial defects, show a good appearance and increase the elegant demeanor, and people hope to beautify themselves through the use of cosmetics, to shape a second "self". Therefore, people use cosmetics not only to obtain material satisfaction but also to seek spiritual and mental pleasure.

\subsection{Characteristics of Advertisement}

David Ogilvy (1985) states: "Make it simple. Make it memorable. Make it inviting to look at. Make it fun to read." In other words, he believes the language of the advertisement should be easy to understand to be acceptable and be memorized by people from all walks of life. Thus, simple words are often used in advertising English. Such as: Just do it.

Above is a vintage advertisement. It has one same feature that is all words are easy to understand. This makes the purports of advertising so clear that every person can understand and memorize them.

Besides, advertisements have many other characteristics, and advertising is purposeful, planned, and continuous. Advertising is beneficial to both the advertiser and the intended consumers. It enables users and consumers to get useful information and to choose the right products. That is the function of the advertisement as well, and the author will discuss it in the next section.

\subsection{Functions of Advertisement}

Firstly, according to Jakobson (1995), language is referential, which means language is used to convey messages and information. In the 1960s, David Ogilvy also emphasized the value of advertising messages. Besides, Crystal \& Davy (1983) said advertising has the function of informing, which means to tell the public about a product or a service to encourage people to buy or use it. Fundamentally, advertising is a vehicle to represent the virtues and advantages of products.

Secondly, language is conative Jakobson (1995). That is to say, advertising can persuade and influence others in specific ways. Meanwhile, it is the most significant function of advertisements. So, producers apply proper tactics to beauty advertisements to encourage consumption. The more people pay attention to this advertisement, the more people will buy it.

Thirdly, language is emotive Jakobson (1995), and it can be used to express attitudes, feelings, and information. Thus, it can influence consumers psychologically. Usually, cosmetic advertising products catch female consumers' peculiarities of consumption, through using emotive words. In this way, the goal of enhancing consumption will be achieved.

In a nutshell, numerable advertisements create consumption needs, stimulate competition to promote the quality of products and services, no matter how big 
the differences among them, they have the same goal that is letting consumers accept their products or services (Bradford \& Jakobson, 1994).

\section{Literature Review}

\subsection{Previous Studies on Cosmetic Advertisements}

Wang Xiaohong's (2006) master's degree thesis, The Application of Rhetorical Devices in Advertising English, said rhetoric plays a decisive role in many linguistic techniques of advertising language. It enriches the connotation of language and deepens its persuasiveness. This paper mainly analyzes and summarizes the implementation of rhetoric devices in advertising English from the perspective of rhetoric.

Through the investigation of the history of cosmetics, Liu Xiaofang (2010) introduced the structure of cosmetic advertisements and its development in her master-degree thesis, The Use of Language in Cosmetics Advertisements as Means of Informational and Product-descriptive Communication. She also illustrated the functions of cosmetic advertisements to highlight the specific features of the advertisement language.

\subsection{Previous Studies on Rhetoric in Advertisements}

Lei Xin's (2018) master-degree thesis, Rhetorical Research in Advertising Language probes into the use of various rhetorical devices in advertising language from the aspects of pronunciation, vocabulary, and grammar to enhance novelty and persuasiveness and discusses the rhetorical effects of different rhetoric types.

Zhang Qiang's (2015) master-degree thesis, A Study on The Rhetorical Language in English Advertising and its Translation makes the analysis of the application and function of conventional rhetorical devices in English advertising, sorts out the problems and challenges that may be encountered in the translation of English advertising rhetoric and proposes feasible translation strategies and solutions to different situations under the guidance of methodology for translators' reference.

\section{Modification and Rhetorical Devices in Cosmetic Advertisements}

\subsection{Lexical Modification in Advertisements}

\subsubsection{Use of Numerals}

Now we have entered the digital era. The number is filled with every corner of daily life; the use of numerals in advertising slogans has become a natural phenomenon. Although digital words are least associative than other types of words, the accuracy of the meaning of digital words can make the advertising content more objective and accurate, giving people a sense of rigorous credibility. The use of numerals is a common characteristic of advertisements, and it conveys the effects of products to consumers more specifically and objectively. At the same time, it highlights the effect of products, intriguing consumers intensely. 
Firstly, the use of numerals aims to highlight product features, which can be testified by the following two examples.

1) Sublime skin revitalization in one week.

2) See younger-looking skin in just four weeks.

These examples are linked with time, like one week, four weeks. They show the products can be useful in a short time, in line with the consumers' psychology of achieving youth eagerly. In this way, it is easier to attract the interest of the audience, especially the middle-aged female consumers who are sensitive to the age and eager to become young, and the advertisement is more likely to stimulate their purchasing desire. In addition, more examples can be given to certify the above point of views, such as:

3) Voluminous mascara for up to 24 hours of wear.

4) A juicy, waltermelon-flavored lip balm that delivers constant 24-hour moisture and a smooth, natural shine.

5) A daily, non-stripping toner with real rose petals and hyaluronic acid that minimize pores while increasing hydration by $46 \%$ for 6 hours.

These three examples show the long-lasting features of these products. Although these advertisements contain exaggerations to some degree, they can significantly attract consumers, which reach the advertisement creators' goal.

Secondly, comparing to the content of advertisements, more consumers tend to believe the actual feedbacks from other consumers. Thus, advertisements often use users' feedback to add reliability, which can be demonstrated by these examples:

1) $91 \%$ reported it smoothed and hydrated by morning.

2) $92 \%$ said it immediately reduced the appearance of fine lines and wrinkles.

3) $93 \%$ noticed it increased the radiance of the eye area.

4) $97 \%$ said it firmed the eye area after four weeks.

These examples are indeed using the experience of consumers, which can deeply provoke the desire to buy the product. These comments are the real feelings of users who have bought the products. Compared with the merchants, consumers are more likely to trust the experience of other consumers. This series of numbers encourage consumers' desire to purchase and can help potential consumers choose the right products for themselves.

\subsubsection{Use of Material Words}

Material words are words used in cosmetic advertisements to express the materials and ingredients used in products. Material words are not common in other kinds of advertisements, but they are an indispensable part of cosmetic advertisements. With the development of science and technology, the prosperity of the beauty industry, the upgrading of new products, a large number of material words appear in the cosmetics advertising language. The proper introduction of material words in cosmetic advertisements can be used to reflect the precious and rare formula as well as the high brand value. It can be reflected in the following examples: 
1) Black tea instant perfecting mask.

2) An instant hydrating mask with real rose petals suspended in a silky gel.

3) This is a lipstick with hyaluronic acid and vitamin $E$.

4) White caviar serum.

5) Our cleansing oil, infused with a blend of botanical oils formulated to remove long-wearing eye makeup. Kukui nut, white water lily, and goji berry extract helps skin feel instantly softened, while jasmine helps skin feel nourished.

In these examples, black tea, white caviar, rose, kukui nut, lily, jasmine are all words for the materials, that gives consumers a feeling of these commodities take effects. Therefore, they are willing to pay for that, especially those elderly female consumers, they have heartily willing to keep youth, and they can afford them. With the development of technology, more and more rare and sufficient materials are used in beauty products, so they become new selling points.

\subsubsection{Use of Comparative Words}

The use of comparative can show the advantages of a product over other products, and advertisements use comparative to represent the effects of products, which is a salient feature in cosmetic advertisements, such as:

1) Your secret to preserve younger-looking skin.

2) Makeup primer for a smoother and more refined complexion in an instant!

The first example shows that this product can help regain young skin; the second example shows the distinct effects of this product are smooth and refine skin.

\subsubsection{Use of Pseudo-Technical Words}

Another striking feature of cosmetic language is that chemical or biological science terms are used more frequently in cosmetic language than in any other advertising language (except for medical and pharmaceutical ads). These ads dazzle consumers with words they do not use every day, making them more inclined to buy. For examples:

1) It is made with amino acid-rich soy proteins, calming cucumber extract, and balancing rosewater.

2) Micro-free optical pearls blur imperfections, as vitamin B\&E and glycerine nourish the skin.

3) Hydrafresh Anti-Ox Grape Seed Hydrating.

In these examples, amino acid and glycerine are words that we rarely use in our daily life, the use of these words proves that the product has a unique formula or technology, that will reach the purpose of encouraging consumption.

\subsection{Rhetorical Devices in Advertisements}

Rhetoric is a kind of language activity that uses a variety of linguistic means to achieve the best possible effect in the process of using language. The most beautiful expression is reflected in the accuracy of the use of words, the clarity of the semantics, and whether the sentences can appeal to people. Only proper and in- 
telligent use of rhetoric can make the language vivid and full of artistic charm.

Advertising is an art, and rhetorical skills of advertising language are an essential aspect of its art form. Only by making good use of rhetorical skills can we accurately convey the content to be expressed by advertising, to attract the attention of the audience and achieve the purpose of advertising. For the sake of women's emotional needs and consumer psychology, the cosmetic advertisement should pay more attention to the use of rhetoric skills to enhance the artistic effect of the slogan.

Commodity advertisement requires concise and comprehensive words and is strictly limited in length for they are economical products, so it is particularly important to use as few words as possible to convey the most useful information and to catch the attention of the audience. Therefore, most advertising uses the form of short sentences. Besides, the use of appropriate rhetorical devices can help to make sure they can be better remembered. Moreover, to enhance the beauty of language through the use of rhetorical devices is of great importance.

In this section, the author will mainly introduce appropriate rhetorical devices in cosmetic advertisements.

\subsubsection{Simile}

According to Pandya (1977), "Similes are useful in advertising because they can express an emotional connection to a product." The simile is a kind of joint strategy which is widely used in literature creation; through this kind of strategy, the author mostly compares objects to concrete things that have a positive feeling. Such as the following examples:

1) An ultra-hydrating face mask famous for its cloud-like whipped texture.

2) For smooth, refined, water-oil balanced, and crystal-like transparent skin.

3) A silky, weightless formula is instantly comforting and helping skin look balanced throughout the day.

4) Long-lasting, velvety lip liner.

5) Miss Dior is a hymn to love, emblematic of Dior's femininity and Couture spirit.

The first four examples all use nice words such as cloud, crystal, silk, and velvet as the vehicles. In the first example, a mask is compared as a cloud that shows the mask is light and thin, and it is easy to remove, in the third example, blush is compared to silk and cream, and this highlights the texture of this blush, the fine and smooth will attract more consumers. In the fifth example, the producer compares perfume to a hymn that is a type of song, written explicitly for praise, adoration or prayer, this shows young girls' yearn for love, and it adds a sense of mystery of this perfume.

\subsubsection{Personification}

Personification means to personalize things and turn things that do not have human actions and feelings into the same appearance with human actions and feelings; it endows things with the characteristics of human behavior, vividly ex- 
press the feelings of the author, let the reader feel the described objects appear livelier. Following examples reflect this kind of rhetorical device:

1) Your skin will tell you what it needs, and we will tell you what works.

2) Olay, your best moisturizer, comes in a little Red Jar.

3) Fresh creates beauty products that perform with experiences that transform.

In these examples, the author compares skin and moisturizer to people. Skin can talk to you about his needs, and moisturizer will come to you in a red jar, this will impress consumers a lot because products are no longer emotionless objects, but living creatures.

\subsubsection{Hyperbole}

Hyperbole is a rhetorical mode that exaggerates or narrows the image, feature, function, and degree of things to achieve specific emotional effects. The rhetorical devices of hyperbole use exaggerated methods to highlight the essence of things or to strengthen some feelings of the author, foil the atmosphere, and arouse the reader's association. The hyperbole in cosmetic advertisements always exaggerates the function of products. Look at the next advertisements:

1) Sublime skin revitalization in one week.

2) See younger-looking skin in just four weeks.

3) Voluminous mascara for up to 24 hours of wear.

4) In 1 week, the skin looks refreshed, replumbed. In 1 month, skin appears renewed, vibrant, and full of life.

Look at the first two examples, the skin may turn better after using these products, but it is hard to say in just one week or one month skin will become different from before, it is impossible. In the third example, the advertising tells consumers that this mascara could keep eyelashes voluminous for a whole day, but in reality, little people will wear mascara for a day, so it lacks evidence that the product affects as the advertising said. Nevertheless, the use of hyperbole does stimulate consumption.

\subsubsection{Pun}

Pun usually can be divided into a homophonic pun and homographic pun. Homophonic means two or more different words are similar or the same sound. Homophonic pun uses two homophonic words in one sentence or phrase to produce a pun, which is commonly seen in advertising (Zhang, 2015). Such as:

1) Fresh skin starts here.

2) Where fresh goes, beauty follows.

3) Dior Addict.

In a specific language context, the use of polysemic or homophonic words to deliberately make a statement with two meanings, this rhetorical device is called a pun. Puns can make the language implicit, humorous, and can deepen the meaning of the word, to give a deep impression.

The first two examples are both advertisements of brand "Fresh" in two ex- 
amples, fresh means both the name of this brand and feelings of new, pleasantly clean, pure or cool, bright and appealing. In the third example, the Dior addict is a kind of lipstick. The addict not only means the brand name but implies that consumers will addict to this lipstick.

\subsubsection{Antithesis and Parallelism}

Antithesis is a rhetorical text pattern in which the presenter intentionally organizes two language units with the same number of words, the same syntax or the similarity in pairs, and realizes the best effect of expression and expression through the proper and harmonious audio-visual aesthetic form. Antithesis is also one of the most common rhetorical devices in cosmetics advertising language because antithesis can make the text pattern present the beauty of visual tidiness, and it is easy to read for the memory of the recipient. In contrast, the memory of visual reading and hearing plays a vital role in advertising language. Some examples are listed below:

1) A year later, not a day older.

2) Beauty comes from the heart, beauty comes from Maybelline.

3) The more I live, the younger I am, the more you use it, the better you feel.

4) I will never forget her kiss, her smile, her perfume.

The first three examples are using antithesis. The last is the use of parallelism. The difference between antithesis and parallelism is the parallel structure of three or more sentences; the antithesis is restricted to two sentences. Moreover, parallelism is not as strict as antithesis; the number of words in parallel sentences may not be precisely equal.

\section{Irregularities in the Use of Rhetorical Devices and Their Causes}

The examples in the previous chapters are all statements that their use of language is standard, their rhetoric is appropriate, and they reach the anticipative propaganda goal. However, in our real life, the real standard, pleasant, vibrant personality of cosmetics advertising language is not shared. Makeup words, false content, vulgar taste, and so on need to be improved.

Next, in this part, the author will summarize the noticeable irregularities in the cosmetics advertising language and make a psychological analysis of these phenomena, and finally, give some suggestions on the rhetoric conventions accordingly.

\subsection{False Information}

At present, many cosmetic slogans use exaggerated art techniques to win the audience's eye and improve the publicity effect, but the use of exaggerated rhetoric techniques should follow the principle of moderation. The phenomenon of exaggerating errors in cosmetics advertisements is often reflected in the slogan exaggerating the efficiency of cosmetics at will, which is often "famous in the world" "the first in the country", or boasting of "effective in 30 days", "eternal 
youth". Not only will make the mature audience feel grandiose distortion, but it also will make the stimulation and tend to dull, and so on. Deceptive advertising not only harms consumers but ultimately damages the image and credibility of the business. Given this phenomenon, the law has explicit provisions. Article 4 of the Advertisement Law of PRC indicates: "An advertisement may not contain any false and deceiving information, and may not cheat or misguide consumers."

\subsection{Lack of Authenticity}

In today's fierce competition in the cosmetics market, cosmetics manufacturers and copywriters are often driven by economic interests to choose those exaggerated words of advertising as their propaganda language, which is called false advertising. Many cosmetic advertisements contain superlatives such as "first" and "most" or use absolute terms such as "completely" and "never before". These overly exaggerated advertisements not only convey false information and mislead consumers, but also bring about many adverse effects on their brand image.

\subsection{Causes of the Irregularities}

During the survey of examples, the author found some abnormal phenomena, such as malicious content, mechanical imitation, and so on. These phenomena are not without causes. In this chapter, the author will explain the causes of them in depth.

\subsubsection{Psychological Factors}

David Ogilvy said: "Before you can have a share of the market, you must have a share of mind (1985)." So, the mental factor is a significant reason for advertising. However, nowadays, the position of the advertisement in recent commercial activity is more and more conspicuous. On the one hand, the social transformation, diversified advertising demands, and diversified propaganda modes are increasingly influencing consumers' consumption concept and purchasing behavior. On the other hand, after meeting the demand for food and clothing, people's understanding of cosmetics has gone through a process from the fundamental necessities of life to the present symbols of identity and dreams, and people's psychological changes have also affected the change of advertising appeals. In this case, more and more cosmetics advertisements begin to contain such words as "luxury", "top class", "noble" and so on, which not only makes the extravagance of the spread of the whole society but also makes similar, imitation and other phenomena in cosmetics advertisements are prevalent.

\subsubsection{Marketing Factors}

With the improvement of people's living standard, people's values, consumption concept, and lifestyle have changed dramatically. When to maximize the effectiveness of advertising, cosmetics have become a symbol of status and carry 
people's dreams of youth and beauty. This kind of change presented in the advertisement language is due to the product's exaggerated modifications, even connecting it with the life grade and social status. These cosmetic advertisements do not describe the function and effect of the product in detail as before, but continuously enhance the artistic expression of the advertisement, such as a large number of uses of exaggeration, metaphor and other rhetorical devices, to make consumers accept the advice and persuasion of the advertisement, accept and recognize the idea of its advertising, and finally produce the purchase behavior.

\section{Conclusion}

\subsection{Major Findings}

As the carrier of cosmetic product information, cosmetic slogans not only play a propaganda role but also form their unique language style and artistic characteristics. With the rapid development of advertising, advertising language has become one of the most dynamic growth points of language use. The amount of play of cosmetic advertisement is the first among all kinds of advertisements year after year. It should cause the great attention of researchers from linguistics, cultural science, psychology, and so on. We should discuss many new and exciting cosmetics advertising language rhetoric phenomena, and much new language and new problems in-depth. Rhetoric research on cosmetic advertising slogans can not only provide ideas and means for its creation and play a decisive guiding role but also theoretically improve the weak phenomenon of the academic study on cosmetic advertising system, to contribute a little bit to the comprehensive study of linguistics. Also, the combination of linguistic rhetoric research and advertising research in linguistics and sociology, together with research achievements in culture, psychology, and other aspects, will promote the penetration and integration of linguistics and other related disciplines and inject new vitality into the development of linguistics.

This thesis from the perspective of rhetoric, analyzes the characteristics of cosmetic advertising words and sentences, and from the perspective of rhetoric specification it points out that the non-standard phenomena that exist in the cosmetics advertising language, and it probes into the cause of these differentiations psychologically. Finally, it aimed at discussing the problems and causes of cosmetics advertising language, standardization principles. Also, some suggestions are put forward. The author hopes this article can help consumers to improve the ability and level of identifying, interpreting, and appreciating cosmetics advertisements, and consuming cosmetics more rationally. Through the analysis of the problems in the cosmetics, the standardization of the suggestions can help us to stay awake to the nonstandard phenomenon of cosmetics advertising, hoping to attract the attention of relevant departments, cosmetics manufacturers and advertisers, through joint efforts make cosmetics ads out of the "myth," on a standard, healthy and pure development path. 
Due to my limited ability, this paper still has many shortcomings in many aspects. For example, the combination of rhetorical skills in cosmetics advertising with female psychology and social psychology is not in-depth enough. Besides, new rules should be made for the standardization of cosmetics advertising language, and more authorities and scholars should be combined with social psychology, language evolution, and speech field to discuss.

\subsection{Suggestions}

\subsubsection{Strengthening the Construction of Relevant Laws and Regulations}

Although there are provisions in the advertising law explicitly dealing with the administration of cosmetic advertising, the state promulgated the administrative measures on cosmetic advertising in 1993 and revised them in 2005. However, with the rapid development of the economic situation, people's living standards and values are continually changing, cosmetic advertising should be modified accordingly. Otherwise, the disconnection between regulations and reality will provide opportunities for the anomie phenomenon of cosmetic advertisement. In the face of the booming cosmetics market and the ever-changing cosmetics advertising industry, how to better strengthen the norms of the behavior of cosmetics advertising practitioners and better protect the interests of consumers has become an urgent matter. We believe that the country should further refine the provisions of the cosmetic advertising management measures to enhance the operation of reality and re-discuss and study some concepts that need to be defined, such as how to define "exaggeration" and "falsity".

\subsubsection{Improving the Quality of the Creative Advertising Staff}

We know that works reflect the mentality and thoughts of the author to some extent. Similarly, creative advertising personnel to cosmetics, will their values and ideology unwittingly projected on the work, so creative advertising personnel must have a strong social sense of responsibility and professional ethics, have a higher cultural level and good cultural quality to ensure the quality of the cosmetics advertisement. Claude Hopkins, the father of modern advertising, once said, "honesty, objectivity and intellectual honesty are the essential qualities of a professional advertiser." Stable and noble ideological and moral character is a person's foundation, but also the cosmetics advertisement creators need to have the primary accomplishment. To establish a correct world view, outlook on life, and values, with a strong sense of responsibility and sense of mission, in the creation of advertising, we should show trust to consumers.

\section{Conflicts of Interest}

The author declares no conflicts of interest regarding the publication of this paper.

\section{References}

Bradford, R., \& Jakobson, R. (1994). Life, Language and Art. London: Routledge. 
Crystal, D., \& Davy, D. (1983). Investigating English Style. London: Longman.

Jakobson, R. (1995). On Language. Cambridge: Harvard University Press.

Lei, X. (2018). Rhetorical Research in Advertising Language. M.A. Thesis, Guiyang: Guizhou Normal University.

Liu, X, F. (2010). The Use of Language in Cosmetics Advertisements as Means of Informational and Product-Descriptive Communication. M.A. Thesis, Taiyuan: Shanxi University.

Ogilvy, D. (1985). Ogilvy on Advertising. New York: Vintage.

Padya, I. H. (1977). English Language in Advertising: A Linguistic Study of Indian Press Advertising. Delhi: Ajanta Publications.

Wang, X. H. (2006). The Application of Rhetorical Devices in Advertising English. M.A. Thesis, Taiyuan: Taiyuan University of Technology.

Zhang, L. (2010). The Language Arts of Cosmetic Advertisements. M.A. Thesis, Wuhan: Central China Normal University.

Zhang, Q. (2015). A Study on the Rhetorical Language in English Adverstising and Its Translation. M.A. Thesis, Shanghai: Shanghai International Studies University. 